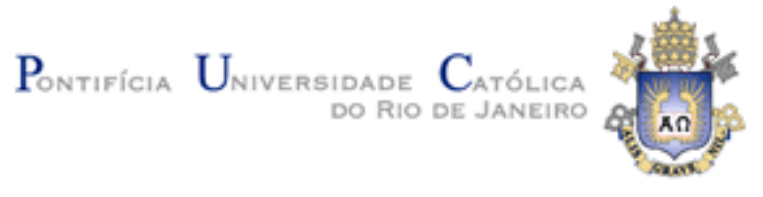

Marcos Martins Pinheiro

Liquidez e Formação de Preço: Evidência do mercado
acionário brasileiro

Dissertação de Mestrado

Dissertação apresentada como requisito parcial para obtenção do título de Mestre pelo Programa de PósGraduação em Economia da PUC-Rio.

Orientador: Prof. João Manoel Pinho de Mello 


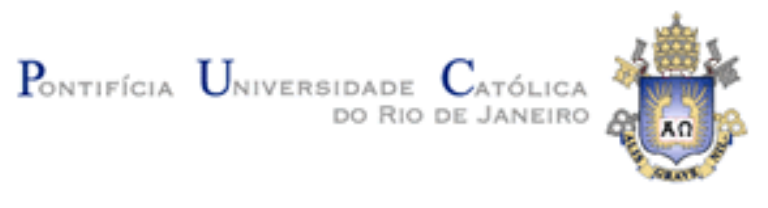

Marcos Martins Pinheiro

\title{
Liquidez e Formação de Preço: Evidência do mercado acionário brasileiro
}

\begin{abstract}
Dissertação apresentada como requisito parcial para obtenção do título de Mestre pelo Programa de PósGraduação em Economia da PUC-Rio. Aprovada pela Comissão Examinadora abaixo assinada.
\end{abstract}

Prof. João Manoel Pinho de Mello

Orientador

Departamento de Economia - PUC-Rio

Prof. Vinicius Nascimento Carrasco

Departamento de Economia - PUC-Rio

Prof. Marco Bonomo

Escola de Pós-Graduação em Economia - FGV

Profa. Mônica Herz

Coordenadora Setorial do Centro de Ciências Sociais - PUC-Rio

Rio de Janeiro, 31 de março de 2010 
Todos os direitos reservados. É proibida a reprodução total ou parcial do trabalho sem autorização da universidade, do autor e do orientador.

\section{Marcos Martins Pinheiro}

Graduou-se em Economia pela Pontifícia Universidade Católica do Rio de Janeiro em 2007.

Ficha Catalográfica

Pinheiro, Marcos Martins

Liquidez e formação de preço: evidência do mercado acionário brasileiro / Marcos Martins Pinheiro; orientador: João Manoel Pinho de Mello. - 2010.

43 f. ; $30 \mathrm{~cm}$

Dissertação (mestrado)-Pontifícia Universidade Católica do Rio de Janeiro, Departamento de Economia, 2010.

Inclui bibliografia

1. Economia - Teses. 2. Liquidez. 3. Microestrutura. 4. Ação. 5. Custo de transação. 6. Modelos de estoque. 7. Curvas de oferta de liquidez. I. Mello, João Manoel Pinho de. II. Pontifícia Universidade Católica do Rio de Janeiro. Departamento de Economia. III. Título. 
Dedico essa dissertação aos meus pais, Dalberto e Therezinha, e ao meu irmão Eduardo, pelo apoio durante todo esse período, sem o qual esse trabalho não teria sido realizado. 


\section{Agradecimentos}

Ao meu professor e orientador, João Manoel Pinho de Mello, pela dedicação e atenção durante todo o mestrado.

Aos professores Vinicius Carrasco e Marco Bonomo, membros da banca examinadora, pelos comentários sobre a dissertação e sugestões.

A todos os professores do Departamento de Economia da PUC-Rio, pelos ensinamentos e pelas valiosas sugestões, especialmente para Walter Novaes e Marcelo Medeiros.

Aos meus amigos economistas, Daniel Ferreira Lima, Henrique Santos, Paulo Vitor de Carvalho e Victor Freitas pelas importantes discussões e por terem dedicado uma parte de seu precioso tempo a mim.

Ao CNPq, pela bolsa fornecida durante o mestrado. 


\section{Resumo}

Pinheiro, Marcos Martins; Mello, João Manoel Pinho de. Liquidez e Formação de Preço: Evidência do mercado acionário brasileiro. Rio de Janeiro, 2010. 43p. Dissertação de Mestrado - Departamento de Economia, Pontifícia Universidade Católica do Rio de Janeiro.

Esta dissertação tem como objetivo inicial testar a hipótese de que um agente não informado pode comprar ou vender qualquer quantidade de uma ação ao preço de mercado no período de um dia. O teste proposto é baseado na relação de preço entre ações de diferentes classes de uma mesma empresa, listadas na Bolsa de Valores de São Paulo, no período de 2004 a 2009. O segundo objetivo é, utilizando dados de microestrutura de mercado, quantificar a compensação paga pela falta de liquidez. Os resultados corroboram a visão de que o investidor marginal não enfrenta curvas de oferta de liquidez perfeitamente elásticas no intervalo de um dia.

\section{Palavras-chave}

Liquidez; microestrutura; ação; custo de transação; modelos de estoque; curvas de oferta de liquidez. 


\section{Abstract}

Pinheiro, Marcos Martins; Mello, João Manoel Pinho de (Advisor). Price Pressure and Market Microstructure: New evidence from the Brazilian stock exchange. Rio de Janeiro, 2010. 43p. MSc. Dissertation Departamento de Economia, Pontifícia Universidade Católica do Rio de Janeiro.

The first goal of this thesis is to test the hypothesis that a non informed agent can buy or sell any quantity of a stock at its current market price in one day. The test is based on the price difference of preferred and common stocks from the same company, listed on the Bolsa de Valores de São Paulo - the Brazilian stock exchange, from 2004 to 2009. Secondly, microstructure data was used to measure the compensation paid by investors because markets lack perfect liquidity. Results corroborate the view that the marginal investor does not face perfectly elastic supply curves of liquidity in one day.

\section{Keywords}

Liquidity; microstructure; stocks; transaction costs; inventory models; liquidity supply. 


\section{Sumário}

1 Introdução 9

2 O Teste 15

2.1. Visão Geral 15

2.2. Seleção da Amostra e Estatísticas Descritivas 18

2.3. Direitos das Classes 23

3 Metodologia 28

4 Resultados 30

5 Conclusão 33

6 Referências Bibliográficas 35

$\begin{array}{lll}7 \text { Apêndice } & 37\end{array}$

$\begin{array}{ll}\text { 7.1. Tabelas } & 37\end{array}$ 


\section{Lista de figuras}

Figura 1. Divisão da quantidade segundo a dispersão dos intermediários financeiros

Figura 2. Desequilíbrios de compra e venda 


\section{Lista de tabelas}

Tabela 1. Concentração no Mercado de Intermediação Financeira

Tabela 2. Composição do Capital Social - Grupo Controlador

Tabela 3. Estatísticas Descritivas das Ações da Amostra

Tabela 4. Direitos de Classes

40

Tabela 5. Resultados da Estimação do Modelo de Correção de Erros 